\title{
Association between matrix metallopeptidase 1 and type 2 diabetes mellitus coexisting with coronary heart disease in a Han Chinese population
}

\author{
Y.Z. Ma ${ }^{1}$, Q.Y. Jiang ${ }^{1}$ and D.Q. Kong ${ }^{2}$ \\ ${ }^{1}$ Department of Blood and Endocrinology, People's Hospital of Zoucheng City, \\ Zoucheng, Shandong, China \\ ${ }^{2}$ Department of Gynaecology and Obstetrics, \\ Maternal And Child Care Service Centre of QuFu City, QuFu, Shangdong, China \\ Corresponding author: Q.Y. Jiang \\ E-mail:WDTfmmu@126.com
}

Genet. Mol. Res. 15 (2): gmr.15027938

Received October 28, 2015

Accepted February 11, 2016

Published June 10, 2016

DOI http://dx.doi.org/10.4238/gmr.15027938

\begin{abstract}
Matrix metallopeptidase 1 (MMP-1) has been reported to be involved in the coexistence of type 2 diabetes mellitus (T2DM) and coronary heart disease (CHD). We sought to examine the association between the $M M P-1$ gene polymorphism and coexistence of T2DM and CHD in a Han Chinese population. We extracted genomic DNA from the peripheral blood of 794 subjects, including 378 patients with coexisting T2DM and CHD and 416 healthy controls. We selected several single nucleotide polymorphisms of the $M M P-1$ gene and genotyped them using the MassARRAY system, before analyzing the data with Haploview 4.0 and SPSS 20.0. A statistical difference was found in the distribution of rs1799750 genotypes between the patient and control groups $(\mathrm{P}=0.041)$. The frequency of the $2 \mathrm{G} / 2 \mathrm{G}$ genotype was 44.25 and $37.0 \%$ among patients and control subjects, respectively. Moreover, the frequency of the $2 \mathrm{G}$ allele was $65.9 \%$ among patients
\end{abstract}


and $59.6 \%$ in the control group, and this difference was found to be significant $(\mathrm{P}=0.010)$. Elevated body mass index was also associated with the 2G/2G genotype. Thus, MMP-1 rs 1799750 may be involved in the development of coexisting T2DM and CHD in the Han Chinese population.

Key words: Type 2 diabetes mellitus; Coronary heart disease; Matrix metallopeptidase 1; Polymorphism

\section{INTRODUCTION}

Type 2 diabetes mellitus (T2DM) frequently coexists with coronary heart disease (CHD) (El-Atat et al., 2004). Increased release of free fatty acids induces the generation of reactive oxygen species (ROS) and elevates oxidative stress in T2DM patients, leading to endothelial dysfunction and promoting the occurrence of CHD (Meerarani et al., 2006). Therefore, T2DM and CHD may interact in patients to intensify the severity of both diseases. However, the exact mechanisms underlying this interaction remain unclear.

Matrix metalloproteinases (MMPs) are endopeptidases that depend upon calcium $\left(\mathrm{Ca}^{2+}\right)$ and contain zinc $\left(\mathrm{Zn}^{2+}\right)$. They belong to a large, highly structurally homologous group of proteases known as the metzincin superfamily (Nagase and Woessner, 1999). These zincpeptidase enzymes use hydrolysis to degrade various extracellular matrix proteins, and are known to be involved in tissue reconstruction and repair, cell migration, angiogenesis, chronic inflammatory reactions, wound healing, and tumor invasion and metastasis $(\mathrm{Vu}$ and Werb, 2000; Visse and Nagase, 2003). Matrix metallopeptidase 1 (MMP-1) forms part of an MMP gene cluster on chromosome 11q22.3. It encodes a secreted enzyme that breaks down interstitial collagen types I, II, and III. MMP-1 can thin and disrupt the fibrous cap of atherosclerotic plaques (Nikkari et al., 1995), and thus may be associated with coronary atherosclerosis, a condition that can easily lead to CHD.

The $1 \mathrm{G} / 2 \mathrm{G}$ polymorphism of $M M P-1$ has been reported to be associated with $\mathrm{CHD}$ in Caucasian populations (Ye et al., 2003). In addition, high glucose concentrations in endothelial cells and macrophages have been shown to increase MMP-1 expression and activity (Death et al., 2003). Heightened glucose concentration also disrupts certain intracellular signal transduction pathways, such as those involving ROS that activate $M M P-1$ expression (King and Wakasaki, 1999; Li and Karin, 1999). Therefore, we speculated that MMP-1 might be associated with coexisting T2DM and CHD.

We chose six single nucleotide polymorphisms (SNPs) of the $M M P-1$ gene to study: rs1799750, rs498186, rs996999, rs2071232, rs1938901, and rs2239008. rs1799750 and rs498186 are located in the $M M P-1$ promoter, whereas rs2239008 lies within the 3 '-untranslated region. The remainder are located in introns or the untranslated region.

\section{MATERIAL AND METHODS}

\section{Subjects}

A total of 378 patients were recruited from our hospital. T2DM diagnoses were made at least six months before enrolment in this study. Patients were defined as diabetic according 
to: 1) a report of having been informed of having diabetes, and/or 2) use of oral hypoglycemic drugs or insulin, or 3) a fasting plasma glucose level $\geq 126 \mathrm{mg} / \mathrm{dL}$, or 4) a 2-h oral glucose tolerance test result $\geq 200 \mathrm{mg} / \mathrm{dL}$. CHD was diagnosed if patients had a history of myocardial infarction or showed abnormal electrocardiographic results. The control group consisted of 416 unrelated healthy subjects having undergone health examinations at our hospital. The study was approved by the local ethics committee, and written informed consent was obtained from all subjects prior to participation.

\section{Genotyping}

Peripheral blood was drawn from a vein into a sterile tube containing ethylenediamine tetraacetic acid. Plasma samples were stored at $-20^{\circ} \mathrm{C}$. Genomic DNA was extracted from frozen peripheral blood samples using a QIAamp Blood Mini Kit (QIAGEN Inc., Valencia, CA, USA) following the manufacturer protocol. Genotyping of all SNPs was performed using the MassARRAY platform (Sequenom, San Diego, CA, USA). Primer extension and polymerase chain reaction were performed using iPLEX enzyme (Sequenom) and HotStarTaq DNA polymerase (QIAGEN, Hilden, Germany), following manufacturer protocols. The resulting spectra were processed with MassARRAY RT software (version 3.0.0.4), and genotype data were analyzed using the MassARRAY Typer program (version 3.4; Sequenom).

\section{Statistical analysis}

All data were analyzed using SPSS 20.0 (IBM Corp., Armonk, NY, USA). Allele and genotype frequencies for each polymorphism and Hardy-Weinberg equilibrium were evaluated by chi-square tests. The association between CHD and each polymorphism was analyzed using chi-square tests or Fisher's exact tests. Odds ratios (ORs) and 95\% confidence intervals (CIs) were used to assess the strength of the association between allele frequencies and CHD. Pairwise linkage disequilibrium (LD) statistics ( $\mathrm{D}^{\prime}$ and $\mathrm{r}^{2}$ ) and haplotype frequencies were computed using Haploview 4.0 (Broad Institute, Cambridge, MA, USA) to construct haplotype blocks.

\section{RESULTS}

All observed genotype distributions in both patient and control groups were in line with Hardy-Weinberg equilibrium $(\mathrm{P}>0.05)$. Strong LD was detected in relation to two pairs of SNPs (rs2239008-rs 1938901 and rs996999-rs498186), which formed two haplotype blocks (D'>0.9, Figure 1). Genotype distributions, allelic frequencies, and haplotypes in the patient and control groups are shown in Tables 1-3.

A statistical difference between the two groups was found in the distribution of $M M P$ 1 gene $\mathrm{rs} 1799750$ genotypes $(\mathrm{P}=0.041)$. The frequency of the $2 \mathrm{G} / 2 \mathrm{G}$ genotype was $44.2 \%$ in patients, and $37.0 \%$ among the controls (Table 2). Moreover, the distribution of rs 1799750 alleles significantly differed between the patient and control groups $(\mathrm{P}=0.010)$. In the former, the frequency of the $2 \mathrm{G}$ allele was $65.9 \%$, while in the latter it was $59.6 \%$ (Table 1 ). Furthermore, we performed an association analysis to determine whether the haplotypes identified were associated with T2DM-CHD risk. However, these haplotypes did not differ between patients and controls (Table 3). Finally, we analyzed the association between rs 1799750 genotype and 
certain clinical characteristics among members of the patient group. The $2 \mathrm{G} / 2 \mathrm{G}$ genotype was found to be associated with higher body mass index (BMI; Table 4).

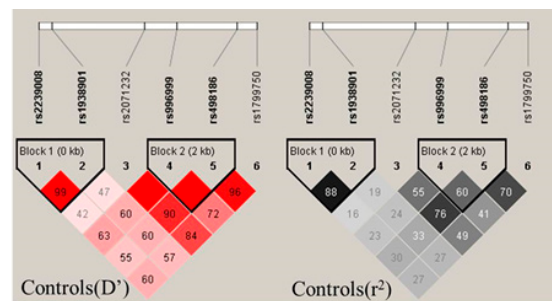

Figure 1. Linkage disequilibrium (LD) plot of $M M P-1$ gene single nucleotide polymorphisms (SNPs) in the control group. Numbers in squares show pairwise $r^{2}$ values. Black squares indicate $r^{2}=1$ (i.e., perfect LD between a pair of SNPs). Empty squares indicate D' = 1 (i.e., complete LD between a pair of SNPs).

Table 1. $M M P-1$ gene polymorphism allele frequencies.

\begin{tabular}{|c|c|c|c|c|c|c|c|}
\hline \multirow[t]{2}{*}{ SNP } & \multirow[t]{2}{*}{ Allele } & \multicolumn{2}{|c|}{ Cases (378) } & \multicolumn{2}{|c|}{ Controls (416) } & \multirow[t]{2}{*}{$P$} & \multirow[t]{2}{*}{ OR $(95 \% \mathrm{CI})$} \\
\hline & & $\mathrm{N}$ & $\%$ & $\mathrm{~N}$ & $\%$ & & \\
\hline \multirow[t]{2}{*}{ rs 1799750} & $2 \mathrm{G}$ & 498 & 65.9 & 496 & 59.6 & 0.010 & $1.308(1.066-1.604)$ \\
\hline & $1 \mathrm{G}$ & 258 & 34.1 & 336 & 40.4 & & \\
\hline \multirow[t]{2}{*}{ rs 498186} & A & 388 & 51.5 & 440 & 52.9 & 0.570 & $0.944(0.775-1.150)$ \\
\hline & $\mathrm{C}$ & 366 & 48.5 & 392 & 47.1 & & \\
\hline \multirow[t]{2}{*}{ rs996999 } & $\mathrm{C}$ & 498 & 65.9 & 542 & 65.1 & 0.760 & $1.033(0.839-1.271)$ \\
\hline & $\mathrm{T}$ & 258 & 34.1 & 290 & 34.9 & & \\
\hline \multirow[t]{2}{*}{ rs2071232 } & $\mathrm{C}$ & 382 & 50.5 & 424 & 51.0 & 0.863 & $0.983(0.807-1.197)$ \\
\hline & $\mathrm{T}$ & 374 & 49.5 & 408 & 49.0 & & \\
\hline \multirow[t]{2}{*}{ rs1938901 } & $\mathrm{C}$ & 408 & 54.0 & 456 & 54.8 & 0.737 & $0.967(0.793-1.178)$ \\
\hline & $\mathrm{T}$ & 348 & 46.0 & 376 & 45.2 & & \\
\hline \multirow[t]{2}{*}{ rs2239008 } & A & 406 & 53.7 & 436 & 52.4 & 0.604 & $1.054(0.865-1.283)$ \\
\hline & G & 350 & 46.3 & 396 & 47.6 & & \\
\hline
\end{tabular}

$\mathrm{SNP}=$ single nucleotide polymorphism, $\mathrm{OR}=$ odds ratio, $\mathrm{CI}=$ confidence interval.

Table 2. $M M P-1$ gene polymorphism genotype frequencies.

\begin{tabular}{|c|c|c|c|c|c|c|c|}
\hline \multirow[t]{2}{*}{ SNP } & \multirow[t]{2}{*}{ Genotype } & \multicolumn{2}{|c|}{ Cases (378) } & \multicolumn{2}{|c|}{ Controls (416) } & \multirow[t]{2}{*}{$\mathrm{P}^{\mathrm{a}}$} & \multirow[t]{2}{*}{$\mathrm{P}^{\mathrm{b}}$} \\
\hline & & $\mathrm{N}$ & $\%$ & $\mathrm{~N}$ & $\%$ & & \\
\hline \multirow[t]{3}{*}{ rs1799750 } & $2 \mathrm{G} / 2 \mathrm{G}$ & 167 & 44.2 & 154 & 37.0 & 0.210 & 0.041 \\
\hline & $2 \mathrm{G} / 1 \mathrm{G}$ & 164 & 43.4 & 188 & 45.2 & & \\
\hline & $1 \mathrm{G} / 1 \mathrm{G}$ & 47 & 12.4 & 74 & 17.8 & & \\
\hline \multirow[t]{3}{*}{ rs498186 } & AA & 94 & 24.9 & 120 & 28.8 & 0.472 & 0.334 \\
\hline & $\mathrm{AC}$ & 200 & 53.1 & 200 & 48.1 & & \\
\hline & $\mathrm{CC}$ & 83 & 22.0 & 96 & 23.1 & & \\
\hline \multirow[t]{3}{*}{ rs996999 } & $\mathrm{CC}$ & 164 & 43.4 & 178 & 42.8 & 0.753 & 0.932 \\
\hline & $\mathrm{CT}$ & 170 & 45.0 & 186 & 44.7 & & \\
\hline & TT & 44 & 11.6 & 52 & 12.5 & & \\
\hline \multirow[t]{3}{*}{ rs2071232 } & $\mathrm{CC}$ & 101 & 26.7 & 118 & 28.4 & 0.051 & 0.782 \\
\hline & $\mathrm{CT}$ & 180 & 47.6 & 188 & 45.2 & & \\
\hline & TT & 97 & 25.7 & 110 & 26.4 & & \\
\hline \multirow[t]{3}{*}{ rs 1938901} & $\mathrm{CC}$ & 117 & 31.0 & 118 & 28.4 & 0.168 & 0.132 \\
\hline & $\mathrm{CT}$ & 174 & 46.0 & 220 & 52.9 & & \\
\hline & TT & 87 & 23.0 & 78 & 18.8 & & \\
\hline \multirow[t]{3}{*}{ rs2239008 } & $\mathrm{AA}$ & 115 & 30.4 & 106 & 25.5 & 0.105 & 0.115 \\
\hline & $\mathrm{AG}$ & 176 & 46.6 & 224 & 53.8 & & \\
\hline & GG & 87 & 23.0 & 86 & 20.7 & & \\
\hline
\end{tabular}

$\mathrm{P}^{\mathrm{a}}$ represents $\mathrm{P}$ values from tests of Hardy-Weinberg equilibrium in the healthy control group. $\mathrm{P}^{\mathrm{b}}$ signifies $\mathrm{P}$-values from tests of genotype frequency differences between the case and control groups. SNP = single nucleotide polymorphism. 
Table 3. $M M P-1$ gene polymorphism haplotype frequencies.

\begin{tabular}{|c|c|c|c|c|c|}
\hline \multicolumn{3}{|c|}{ Haplotype } & \multicolumn{2}{|c|}{ Gene counting (frequency \%) } & \multirow[t]{2}{*}{$\mathrm{P}$} \\
\hline Name & & & Cases & Controls & \\
\hline \multicolumn{6}{|c|}{ Block 1 rs2239008-rs1938901 } \\
\hline$\overline{\text { HAP1 }}$ & A & $\mathrm{C}$ & 201 & 217 & 0.776 \\
\hline$\overline{\text { HAP2 }}$ & G & $\mathrm{T}$ & 172 & 187 & 0.876 \\
\hline \multicolumn{6}{|c|}{ Block 2 rs996999-rs498186 } \\
\hline$\overline{\text { HAP1 }}$ & $\mathrm{C}$ & A & 193 & 220 & 0.607 \\
\hline HAP2 & $\mathrm{T}$ & $\mathrm{C}$ & 127 & 145 & 0.709 \\
\hline HAP3 & $\mathrm{C}$ & $\mathrm{C}$ & 56 & 51 & 0.643 \\
\hline
\end{tabular}

\begin{tabular}{|c|c|c|c|c|}
\hline Variable & $1 \mathrm{G} / 1 \mathrm{G}$ & $1 \mathrm{G} / 2 \mathrm{G}$ & $2 \mathrm{G} / 2 \mathrm{G}$ & $\mathrm{P}$ \\
\hline BMI $\left(\mathrm{kg} / \mathrm{m}^{2}\right)$ & & & & 0.008 \\
\hline$\leq 24$ & 56 & 60 & 6 & \\
\hline$>24$ & 111 & 104 & 41 & \\
\hline Smoking & & & & 0.345 \\
\hline Yes & 84 & 79 & 18 & \\
\hline No & 83 & 85 & 29 & \\
\hline Alcoholism & & & & 0.061 \\
\hline Yes & 98 & 75 & 24 & \\
\hline No & 69 & 89 & 23 & \\
\hline Disease duration (years) & & & & 0.056 \\
\hline$<5$ & 76 & 54 & 18 & \\
\hline $5-10$ & 59 & 61 & 21 & \\
\hline$>10$ & 32 & 49 & 8 & \\
\hline Age (years) & & & & 0.294 \\
\hline$\leq 40$ & 37 & 29 & 6 & \\
\hline$\geq 41$ & 130 & 135 & 41 & \\
\hline
\end{tabular}

$\mathrm{BMI}=$ body mass index.

\section{DISCUSSION}

Significant evidence exists showing that high blood glucose is a primary risk factor for cardiovascular disease (King and Wakasaki, 1999; Li and Karin, 1999). T2DM patients suffering from CHD are at increased risk of mortality compared to those without CHD (Kannel and McGee, 1979; Fuller et al., 1983).

Levels of MMPs are elevated in cultivated diabetic fibroblasts compared with those from healthy controls. This is significant because these cells play an important role in wound healing (Lobmann et al., 2006). In endothelial cells and macrophages from diabetes patients, high glucose levels increase the expression of MMPs and promote CHD (Death et al., 2003). In addition, diabetes mellitus enhances vascular MMP activity and increases the likelihood of developing CHD, as it is mediated by a ROS-sensitive pathway (Uemura et al., 2001; Ye et al., 2003). The above-cited evidence shows that T2DM-CHD coexistence may be associated with MMP activity.

In this study, we found that the $M M P-1$ gene rs 1799750 polymorphism was associated with coexisting T2DM and CHD. The body of research relating to this polymorphism has been growing in recent years. rs 1799750 is located in the $M M P-1$ promoter region, and its $2 \mathrm{G}$ allele is known to increase transcription of this gene (Rutter et al., 1998; Affara et al., 2011). This MMP-1 1G/2G polymorphism may influence the prevalence of CHD (Ye et al., 2003; Horne et al., 2007). Moreover, it has been associated with coexisting T2DM and CHD in Caucasian populations, and the $2 \mathrm{G}$ allele is present at a higher frequency in these patients than in healthy 
control subjects (Drzewoski et al., 2008). Such findings are consistent with our results, which support the association between rs1799750 and coexisting T2DM and CHD.

The $M M P-1$ promoter is known to contain essential response elements to the transcription factors activator protein-1 (AP-1) and E twenty-six (Ets), which can be active in the presence of high glucose levels. Insertion of an extra guanine at position -1607 in this promoter creates an additional Ets binding site (5'-GGAT-3') adjacent to the AP-1 site at -1602. Compared with the $1 \mathrm{G}$ allele, the $2 \mathrm{G}$ allele significantly increases $M M P-1$ transcriptional activity, which in turn promotes coexisting T2DM and CHD. We also found that the $2 \mathrm{G} / 2 \mathrm{G}$ genotype is associated with higher BMI.

The other polymorphisms under investigation, rs498186, rs996999, rs2071232, rs1938901, and rs2239008, showed no statistically significant differences in distribution between the study groups. Neither of the $M M P-1$ haplotype blocks identified, rs2239008rs1938901 and rs996999-rs498186, were associated with T2DM-CHD risk.

In conclusion, the rs1799750 polymorphism in the $M M P-1$ promoter region may be associated with coexisting T2DM and CHD.

\section{Conflicts of interest}

The authors declare no conflict of interest.

\section{REFERENCES}

Affara M, Dunmore BJ, Sanders DA, Johnson N, et al. (2011). MMP1 bimodal expression and differential response to inflammatory mediators is linked to promoter polymorphisms. BMC Genomics 12: 1-13. http://dx.doi. org/10.1186/1471-2164-12-43

Death AK, Fisher EJ, McGrath KC and Yue DK (2003). High glucose alters matrix metalloproteinase expression in two key vascular cells: potential impact on atherosclerosis in diabetes. Atherosclerosis 168: 263-269. http://dx.doi. org/10.1016/S0021-9150(03)00140-0

Drzewoski J, Sliwińska A, Przybyłowska K, Sliwiński T, et al. (2008). Gene polymorphisms and antigen levels of matrix metalloproteinase-1 in type 2 diabetes mellitus coexisting with coronary heart disease. Kardiol. Pol. 66: 1042-1048, discussion 1049.

El-Atat F, McFarlane SI and Sowers JR (2004). Diabetes, hypertension, and cardiovascular derangements: pathophysiology and management. Curr. Hypertens. Rep. 6: 215-223. http://dx.doi.org/10.1007/s11906-004-0072-y

Fuller JH, Shipley MJ, Rose G, Jarrett RJ, et al. (1983). Mortality from coronary heart disease and stroke in relation to degree of glycaemia: the Whitehall study. Br. Med. J. (Clin. Res. Ed.) 287: 867-870. http://dx.doi.org/10.1136/ bmj.287.6396.867

Horne BD, Camp NJ, Carlquist JF, Muhlestein JB, et al. (2007). Multiple-polymorphism associations of 7 matrix metalloproteinase and tissue inhibitor metalloproteinase genes with myocardial infarction and angiographic coronary artery disease. Am. Heart J. 154: 751-758. http://dx.doi.org/10.1016/j.ahj.2007.06.030

Kannel WB and McGee DL (1979). Diabetes and cardiovascular risk factors: the Framingham study. Circulation 59: 8-13. http://dx.doi.org/10.1161/01.CIR.59.1.8

King GL and Wakasaki H (1999). Theoretical mechanisms by which hyperglycemia and insulin resistance could cause cardiovascular diseases in diabetes. Diabetes Care 22 (Suppl 3): C31-C37.

Li N and Karin M (1999). Is NF-kappaB the sensor of oxidative stress? FASEB J. 13: 1137-1143.

Lobmann R, Pap T, Ambrosch A, Waldmann K, et al. (2006). Differential effects of PDGF-BB on matrix metalloproteases and cytokine release in fibroblasts of Type 2 diabetic patients and normal controls in vitro. J. Diabetes Complications 20: 105-112.http://dx.doi.org/10.1016/j.jdiacomp.2005.05.013

Meerarani P, Badimon JJ, Zias E, Fuster V, et al. (2006). Metabolic syndrome and diabetic atherothrombosis: implications in vascular complications. Curr. Mol. Med. 6: 501-514. http://dx.doi.org/10.2174/156652406778018680

Nagase H and Woessner JF, Jr. (1999). Matrix metalloproteinases. J. Biol. Chem. 274: 21491-21494. http://dx.doi. org/10.1074/jbc.274.31.21491 
Nikkari ST, O’Brien KD, Ferguson M, Hatsukami T, et al. (1995). Interstitial collagenase (MMP-1) expression in human carotid atherosclerosis. Circulation 92: 1393-1398. http://dx.doi.org/10.1161/01.CIR.92.6.1393

Rutter JL, Mitchell TI, Butticè G, Meyers J, et al. (1998). A single nucleotide polymorphism in the matrix metalloproteinase-1 promoter creates an Ets binding site and augments transcription. Cancer Res. 58: 5321-5325.

Uemura S, Matsushita H, Li W, Glassford AJ, et al. (2001). Diabetes mellitus enhances vascular matrix metalloproteinase activity: role of oxidative stress. Circ. Res. 88: 1291-1298. http://dx.doi.org/10.1161/hh1201.092042

Visse R and Nagase H (2003). Matrix metalloproteinases and tissue inhibitors of metalloproteinases: structure, function, and biochemistry. Circ. Res. 92: 827-839. http://dx.doi.org/10.1161/01.RES.0000070112.80711.3D

Vu TH and Werb Z (2000). Matrix metalloproteinases: effectors of development and normal physiology. Genes Dev. 14: 2123-2133.http://dx.doi.org/10.1101/gad.815400

Ye S, Gale CR and Martyn CN (2003). Variation in the matrix metalloproteinase-1 gene and risk of coronary heart disease. Eur. Heart J. 24: 1668-1671.http://dx.doi.org/10.1016/S0195-668X(03)00385-3 